ERRATUM

\title{
Impact of ethnicity on gestational diabetes identified with the WHO and the modified International Association of Diabetes and Pregnancy Study Groups criteria: a population-based cohort study
}

Anne K Jenum ${ }^{1,2,3, *}$, Kjersti Mørkrid ${ }^{1,2, *}$, Line Sletner ${ }^{1,2,4}$, Siri Vange ${ }^{5}$, Johan L Torper ${ }^{6}$, Britt Nakstad ${ }^{2,4}$, Nanna Voldner, ${ }^{5}$, Odd H Rognerud-Jensen ${ }^{3}$, Sveinung Berntsen ${ }^{7,8}$, Annhild Mosdøl ${ }^{3}$, Torild Skrivarhaug ${ }^{9}$, Mari H Vårdal ${ }^{10}$, Ingar Holme ${ }^{11}$, Chittaranjan S Yajnik ${ }^{12}$ and Kåre I Birkeland ${ }^{1,2}$

The authors and the journal apologise for an error in the name of the fourth author of this article published in the February 2012 issue, Vol 166, pp 317-324. The correct name of the author is Siri Vangen.

European Journal of Endocrinology 166561 